\title{
Application of X-ray absorption near edge spectroscopy to the study of the effect of sulphur on selenium uptake and assimilation in wheat seedlings
}

\author{
Q.Q. HUANG ${ }^{1,2}$, Q. WANG ${ }^{1}$, Y.N. WAN ${ }^{1}$, Y. YU ${ }^{1}$, R.F. JIANG ${ }^{1}$, and H.F LI $^{1 *}$ \\ College of Resources and Environmental Sciences, China Agricultural University, Beijing 100193, P.R. China ${ }^{1}$ \\ Institute of Agro-Environmental Protection, Ministry of Agriculture, Tianjin 300191, P.R. China ${ }^{2}$
}

\begin{abstract}
Selenium (Se) is an essential trace element for humans and animals. A hydroponic experiment was performed to study the effects of sulphur (S) on Se uptake, translocation, and assimilation in wheat (Triticum aestivum L.) seedlings. Sulphur starvation had a positive effect on selenate uptake and the form of Se supplied greatly influenced Se speciation in plants. Compared with the control plants, Se uptake by the S-starved plants was enhanced by 4.81 -fold in the selenate treatment, and selenate was readily transported from roots to shoots. By contrast, S starvation had no significant effect on selenite uptake, and selenite taken up by roots was rapidly converted to organic forms and tended to accumulate in roots. X-ray absorption near edge spectroscopy (XANES) analysis showed that organic forms of selenium, including selenocystine, Se-methyl-selenocysteine (MeSeCys), and selenomethionine-Se-oxide, were dominant in the plants exposed to selenite and accounted for approximately $90 \%$ of the total Se. Whereas selenate remained as the dominant species in the roots and shoots exposed to selenate, with little selenate converted to selenite and MeSeCys. Besides, sulphur starvation increased the proportion of inorganic Se species in the selenate-supplied plants, but had no significant effects on Se speciation in plants exposed to selenite. The present study provides important knowledge to understand the associated mechanism of Se uptake and metabolism in plants.
\end{abstract}

Additional key words: selenate, selenite, XANES.

\section{Introduction}

Selenium, an essential trace element required for human and animal nutrition, has been recognized as a crucial component of several selenoproteins such as glutathione peroxidases (GSHPx), thioredoxin reductase, and iodothyronine-deiodinases (Rayman 2000, Brown and Arthur 2001). It plays important roles in antioxidant function, thyroid hormone metabolism, reproduction, and immune responses (Rayman 2002). Plants are the main source of dietary Se, unfortunately cereal food generally has low Se content (Combs 2001, Williams et al. 2009, Zhu et al. 2009). Therefore, understanding the mechanism of Se uptake and metabolism in plants is of great importance. Although Se is not essential for plants, low doses of Se are believed to be beneficial for them.
Researchers have found that Se may regulate reactive oxygen species (ROS) and antioxidants in stressed plants (Mittler 2002, Cartes et al. 2010, Chu et al. 2010, Yao et al. 2010). However, the associated mechanisms are still unclear.

Plant roots absorb Se from the soil solution predominantly as selenate and selenite (Terry et al. 2000, White et al. 2004, Sors et al. 2005). The selenate is thought to enter root cells via high-affinity sulphate transporters in the plasma membrane (Terry et al. 2000, White et al. 2004, Sors et al. 2005), and it is readily transported from roots to shoots through the xylem with a relatively small proportion assimilated to organic forms (Li et al. 2008, Wang et al. 2015). In contrast, the

Submitted 3 November 2015, last revision 6 August 2016, accepted 18 November 2016.

Abbreviations: APS - ATP sulphurylase; $\gamma$-Glu-MeSeCys - $\gamma$-glutamyl-Se-methyl-selenocysteine; MeSeCys - Se-methylselenocysteine; ROS - reactive oxygen species; $\mathrm{SeCys}_{2}$, - selenocystine; SeMet - selenomethionine; SeOMet - selenomethionine-Seoxide; XANES - X-ray absorption near edge spectroscopy.

Acknowledgements: The National Natural Science Foundation of China (No. 41073094 and No. 41471271) and the special fund for Agro-scientific Research in the Public Interest of China (No. 201303106) financially supported this work. The synchrotron analysis of this research was undertaken at the Shanghai Synchrotron Radiation Facility, Shanghai, China.

* Authors for correspondence; fax: (+86) 10 62731165, e-mail: lihuafen@cau.edu.cn 
mechanism of selenite uptake by plants is poorly understood. Li et al. (2008) suggested that selenite uptake by wheat is probably mediated by phosphate transporters. Zhang et al. (2014) demonstrated that selenite and phosphate share similar uptake mechanisms. Moreover, selenite taken up by roots is readily converted to organic forms and tends to accumulate in roots ( $\mathrm{Li}$ et al. 2008, Wang et al. 2015).

The metabolic pathway of Se assimilation is thought to follow the sulphur assimilation pathway (Terry et al. 2000, Sors et al. 2005). A range of Se species have been identified in plants, including selenate, selenite, selenocystine $\left(\mathrm{SeCys}_{2}\right), \quad$ Se-methyl-selenocysteine (MeSeCys), selenomethionine (SeMet), selenomethionine-Se-oxide (SeOMet), and $\gamma$-glutamyl-Semethyl-selenocysteine ( $\gamma$-Glu-MeSeCys) (Hawkesford and Zhao 2007). Moreover, Se speciation in plant tissues varies with plant species (Kápolna and Fodor 2006, Li et al. 2010, Wang et al. 2015). For example, SeMet is the predominant Se species in most grains such as wheat and rice (Cubadda et al. 2010, Li et al. 2010). By contrast,
MeSeCys is the major Se compound in onion (Kápolna and Fodor 2006). Besides, Se metabolism in plants is also important for human nutrition because the beneficial nutritional value of Se is based not only on the amount but also on its chemical form (Kápolna and Fodor 2006). SeMet and SeCys have high occurrence (Thomson 2004) whereas MeSeCys and $\gamma$-Glu-MeSeCys are more effective inhibitors of tumor formation when compared with other Se species (Rayman et al. 2008).

X-ray absorption near edge spectroscopy (XANES) allows the direct measurement of the chemical species of Se in vivo and recently has been used to analyze Se speciation in plant tissues (Li et al. 2010, Bañuelos et al. 2012, Carey et al. 2012). Because the biochemical characteristics of Se parallel those of $\mathrm{S}$, the existence of $\mathrm{Se}$ and $\mathrm{S}$ competition may affect the uptake, translocation, and assimilation of Se (Hopper and Parker 1999, Terry et al. 2000, White et al. 2004). Thus, objective of the present study was to use XANES to investigate the effect of sulphate on Se uptake and assimilation in wheat supplied with selenate or selenite.

\section{Materials and methods}

Wheat (Triticum aestivum L. cv. Jingdong 8) seeds obtained from the Key Laboratory of Plant Nutrition, China Agricultural University, Beijing, were disinfected in a $30 \%(\mathrm{v} / \mathrm{v}) \mathrm{H}_{2} \mathrm{O}_{2}$ solution for $15 \mathrm{~min}$, rinsed with deionized water, soaked in saturated $\mathrm{CaSO}_{4}$ solution at $25{ }^{\circ} \mathrm{C}$ in the dark overnight, and then germinated in $0.5 \mathrm{mM} \mathrm{CaCl}_{2}$ solution. Wheat seedlings were cultured in a plastic container containing $40 \mathrm{dm}^{3}$ of a modified 1/5 strength Hoagland nutrient solution for one week, then transferred to $2.2 \mathrm{dm}^{3}$ pots (four plants per pot) for 4 weeks. The composition of the Hoagland nutrient solution was $(\mathrm{mM}): 1.0 \quad \mathrm{KNO}_{3}, 0.1 \quad \mathrm{KH}_{2} \mathrm{PO}_{4}, 0.457$ $\mathrm{MgSO}_{4}, 1.0 \mathrm{Ca}\left(\mathrm{NO}_{3}\right)_{2}, 3.0 \times 10^{-3} \mathrm{H}_{3} \mathrm{BO}_{3}, 1.0 \times 10^{-3} \mathrm{MnCl}_{2}$, $1.0 \times 10^{-3}\left(\mathrm{NH}_{4}\right)_{6} \mathrm{Mo}_{7} \mathrm{O}_{24}, 0.2 \times 10^{-3} \mathrm{CuSO}_{4}, 1.0 \times 10^{-3} \mathrm{ZnSO}_{4}$ and $60 \times 10^{-3} \mathrm{Fe}$ (III)-EDTA. The $\mathrm{pH}$ of this solution was buffered at 6.0 with $2 \mathrm{mM}$ morpholinoethanesulphonic acid (MES) and adjusted with $\mathrm{KOH}$. The solution was aerated continuously and renewed every $3 \mathrm{~d}$. Plants were grown in a greenhouse with a 14-h photoperiod, an irradiance of $240 \mu \mathrm{mol} \mathrm{m} \mathrm{m}^{-2} \mathrm{~s}^{-1}$, day/night temperatures of $28 / 20{ }^{\circ} \mathrm{C}$, and a relative humidity of $60-70 \%$. Fiveweek-old seedlings were transferred, to normal or S-deficient nutrient solutions for 1 week. In the S-deficient solution $\mathrm{MgSO}_{4}, \mathrm{CuSO}_{4}, \mathrm{ZnSO}_{4}$ were replaced by the corresponding chlorides. One week later, seedlings were transferred to the normal nutrient solution plus either $10 \mu \mathrm{M}$ selenite as $\mathrm{Na}_{2} \mathrm{SeO}_{3}$ or $10 \mu \mathrm{M}$ selenate as $\mathrm{Na}_{2} \mathrm{SeO}_{4}$. Each treatment was applied in three pots (two plants per pot). After $3 \mathrm{~d}$ of Se treatment, roots were rinsed with deionized water and then transferred to $1 \mathrm{mM}$ $\mathrm{CaSO}_{4}$ solution for 15 min to remove any $\mathrm{Se}$ on the root surfaces. Shoots and roots were then separated, frozen in

liquid nitrogen and ground with liquid nitrogen to a fine powder in a pestle and mortar. Samples were then used for the determination of total Se and Se speciation.

For analysis of total $\mathrm{Se}$ and $\mathrm{S}$ in wheat tissues, powdered plant samples (fresh mass $0.25 \mathrm{~g}$ ) were digested with $8 \mathrm{~cm}^{3}$ of high-purity $\mathrm{HNO}_{3}$ using the microwave sample preparation system (MARS5, CEM, Matthews, NC, USA). The concentrations of Se and S in the digest solution was determined by inductively coupled plasma - mass spectrometry (ICP-MS, 7700ce, Agilent Technologies, Santa Clara, CA, USA) and inductively coupled plasma - atomic emission spectroscopy (ICP-AES, Optima 2000, Perkin Elmer, Waltham, MA, USA), respectively. Blanks and a certified reference material ( $G S B-23$ rice flour) were included in each batch of samples for quality control. The recovery for GSB-23 was 85 - $105 \%$ (Cubadda et al. 2010).

Selenium speciation in wheat seedlings was analysed by synchrotron XANES. XANES spectra of powdered samples were collected using the $B L 14 W 1$ beam at the Shanghai Synchrotron Radiation Facility, Shanghai, China. The storage ring operated at energy of $3.5 \mathrm{GeV}$ with current intensity of 200 to $300 \mathrm{~mA}$. The $B L 14 \mathrm{~W} 1$ beam was equipped with a $\mathrm{Si}$ (111) double-crystal monochromator to obtain the incident X-ray beam. Energy was calibrated using an elemental Se foil (K-edge $12.658 \mathrm{keV}$ ). The ground samples were brushed onto tape in an anaerobic chamber with $\mathrm{O}_{2}$ concentration < $1.0 \mathrm{mg} \mathrm{dm}^{-3}$ in order to avoid oxygen from contacting the samples and restrain the beam-induced oxidation during measurement. The samples were measured in the fluorescence mode using a Ge solid-state detector. The 
power of Se reference compounds was measured in the transmission mode. Se reference compounds were purchased from Sigma (St Louis, MO, USA) and included sodium selenite, sodium selenate, $\mathrm{SeCys}_{2}$, SeMet, and MeSeCys. SeOMet was prepared by reacting SeMet with $3 \%(\mathrm{v} / \mathrm{v}) \mathrm{H}_{2} \mathrm{O}_{2}$ under sonication for $1 \mathrm{~h}$ (Larsen et al. 2004).

Se content in wheat roots and shoots was calculated on the basis of fresh mass. Total Se uptake $\left(\mathrm{T}_{\mathrm{Se}}\right)$, Se uptake by roots, and percentages of Se in wheat roots and shoots were calculated using Equations (1 - 6):

$\mathrm{T}_{\text {Root-Se }}=\mathrm{C}_{\text {Root-Se }} \times$ Root $_{\text {biomass }}$

$\mathrm{T}_{\text {Shoot-Se }}=\mathrm{C}_{\text {Shoot-Se }} \times$ Shoot $_{\text {biomass }}$

$\mathrm{T}_{\mathrm{Se}}=\mathrm{T}_{\text {Root-Se }}+\mathrm{T}_{\text {Shoot-Se }}$
Se uptake $=\mathrm{T}_{\mathrm{Se}} /$ Root $_{\text {biomass-Se }}$

Root-Se [\%] $=\left(\mathrm{T}_{\text {Root }-\mathrm{Se}} / \mathrm{T}_{\text {Se }}\right) \times 100$

Shoot-Se $[\%]=\left(\mathrm{T}_{\text {Shoot-Se }} / \mathrm{T}_{\mathrm{Se}}\right) \times 100$

where $\mathrm{T}_{\text {Root-Se }}$ and $\mathrm{T}_{\text {Shoot-Se }}$ represent the total Se in wheat roots and shoots, respectively; and $\mathrm{C}_{\text {Root-Se }}$ and $\mathrm{C}_{\text {Shoot-Se }}$ are $\mathrm{Se}$ content in wheat roots and shoots, respectively.

Besides, the significance of treatment effects were determined by analysis of variance. Data presented are means \pm SEs $(n=3)$, and the means were compared using least significant difference at the $5 \%$ level of significance. The XANES data of the samples were normalized and analyzed by linear combination fitting using Athena software (Ravel and Newville 2005).

\section{Results}

In this experiment, the treatment of $\mathrm{S}$ starvation was imposed before the exposure of plant roots to Se, and during the period of Se exposure $(3 \mathrm{~d})$, then a normal nutrient solution was supplied to all treatments. Plants grown under $\mathrm{S}$ starvation showed a significant decrease in the fresh mass of both roots and shoots (by about $35 \%$ in roots and $46 \%$ in shoots; data not shown). Besides, $\mathrm{S}$ starvation and Se treatments had substantial effects on $\mathrm{S}$ accumulation in wheat. Compared with the control plants (grown in normal nutrient solution throughout the experiment), $\mathrm{S}$ starvation increased $\mathrm{S}$ content in shoots (approximately $40 \%$ ) probably due to the activation of sulphur transporter, but showed no significant change in roots (Fig. 1). Moreover, the addition of selenate also significantly affected $\mathrm{S}$ content in shoots, but not in roots. Selenate addition increased $\mathrm{S}$ content in shoots approximately by 1.4 -fold, whereas $\mathrm{S}$ starvation did not significantly affect the $\mathrm{S}$ content under the selenite treatment.

Sulphur starvation and the form of Se supplied had significant effects upon Se uptake and distribution in wheat (Table 1). Sulphur starvation had significant effects on Se uptake by wheat roots in the selenate

treatment, but not in the selenite treatment. In wheat plants grown at $10 \mu \mathrm{M}$ selenate for $3 \mathrm{~d}$, S starvation significantly increased Se content in roots and shoots by 4.2-fold and 5.9-fold, respectively, as compared to the control. Consequently, Se uptake by S-deficient plants exposed to selenate was enhanced by 4.81 -fold. Se content was higher in shoots than in roots in plants exposed to selenate, but the opposite was true for selenite-exposed plants. In the selenate treatment, Se content in wheat shoots was 1.5- to 5.5-times higher than in roots, whereas Se content in wheat shoots from the selenite treatment was 9.5- to 12.5-times lower than in roots. Nevertheless, Se species supplied within the nutrient solution had a marked effect on Se distribution between roots and shoots $(P<0.05)$, but $\mathrm{S}$ starvation had no significant effect on the distribution of Se in plants $(P>0.05)$ (Table 1). On average, $85 \%$ of the Se taken up by plants exposed to selenate was distributed to the shoots, whereas only $23 \%$ in the plants from the selenite treatment.

To understand the effect of $\mathrm{S}$ starvation and $\mathrm{Se}$ species supplied on Se assimilation in wheat, XANES

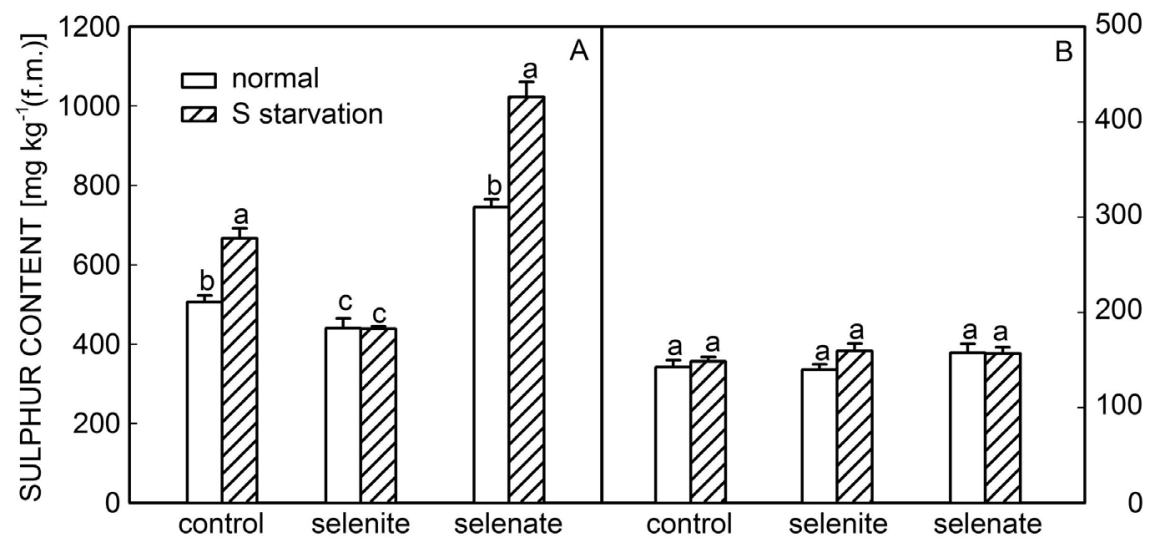

Fig. 1. Effect of S starvation and Se treatments on $\mathrm{S}$ content in wheat shoots $(A)$ and roots $(B)$. Means \pm SEs, $n=3$; different letters indicate significant differences according to LSD multiple comparison test $(P<0.05)$. 
Table 1. Effect of S starvation on the Se uptake and the proportion of Se distributed to shoots by wheat seedlings. Means \pm SEs, $n=3$; different letters within the same column indicate significant differences based on a LSD test $(P<0.05)$.

\begin{tabular}{|c|c|c|c|c|c|}
\hline Treatment & & \multicolumn{2}{|c|}{ Se content $\left[\mathrm{mg} \cdot \mathrm{kg}^{-1}\right.$ (f.m.) $]$} & Se uptake $\left[\mathrm{mg} \cdot \mathrm{kg}^{-1}\right.$ (root f.m.) $]$ & Se in shoots $[\%]$ \\
\hline \multirow[t]{2}{*}{ Selenate } & normal & $1.49 \pm 0.03 \mathrm{c}$ & $2.59 \pm 0.21 b$ & $10.18 \pm 0.15 b$ & $85.42 \pm 0.18 \mathrm{a}$ \\
\hline & S starvation & $6.18 \pm 0.19 b$ & $15.26 \pm 1.12 \mathrm{a}$ & $48.96 \pm 0.43 \mathrm{a}$ & $87.37 \pm 0.73 \mathrm{a}$ \\
\hline \multirow[t]{2}{*}{ Selenite } & normal & $10.50 \pm 0.73 \mathrm{a}$ & $0.84 \pm 0.05 \mathrm{c}$ & $13.68 \pm 0.99 \mathrm{~b}$ & $23.24 \pm 0.29 b$ \\
\hline & S starvation & $10.08 \pm 0.48 \mathrm{a}$ & $1.04 \pm 0.69 \mathrm{c}$ & $13.70 \pm 0.69 b$ & $26.34 \pm 1.39 \mathrm{~b}$ \\
\hline
\end{tabular}

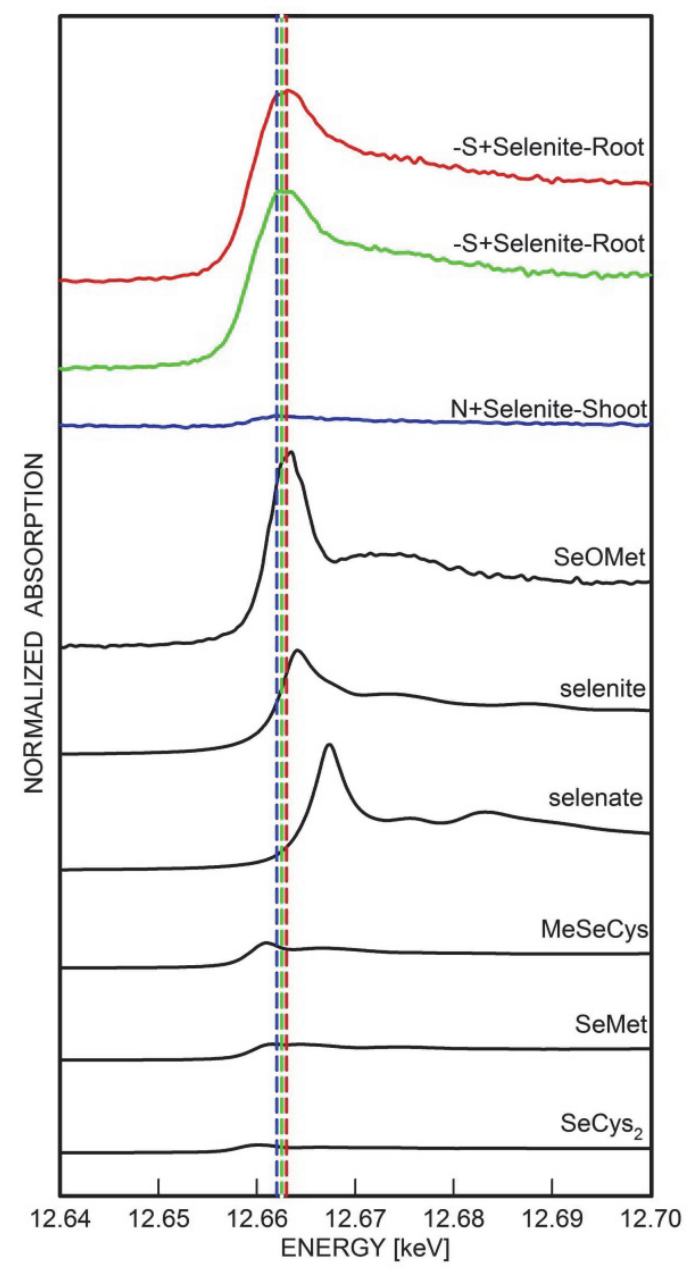

Fig. 2. Normalized Se K-edge XANES spectra of wheat seedlings exposed to $10 \mu \mathrm{M}$ selenite for $3 \mathrm{~d}$. The three vertical dotted lines correspond to the colour line peaks of the three selenite-treated samples. Linear combination fitting was used for the samples (Table 2).

spectra were used to analyze Se speciation in wheat seedlings. Seven samples including wheat roots and shoots were selected for XANES spectra analysis and the total Se content in those samples was determined. Figs. 2 and 3 show the normalized spectra obtained from Se reference compounds and samples. Tables 2 and 3 show

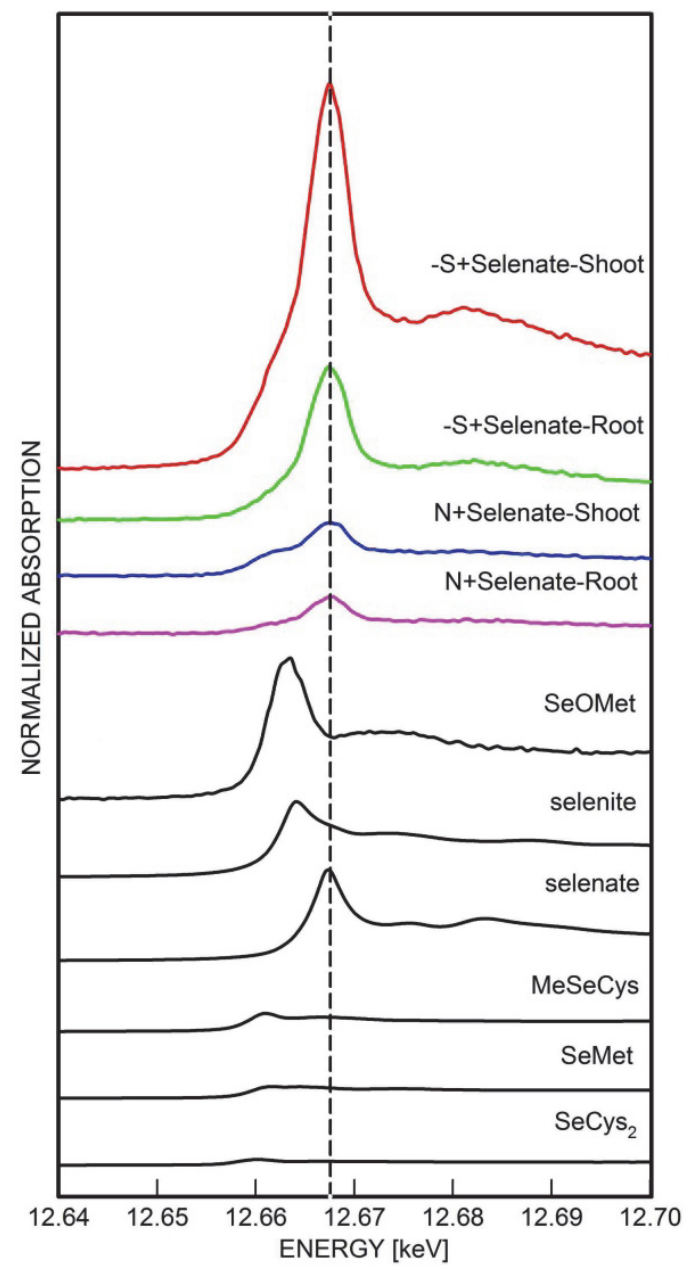

Fig. 3. Normalized Se K-edge XANES spectra of wheat seedlings exposed to $10 \mu \mathrm{M}$ selenate for $3 \mathrm{~d}$. The vertical dotted line corresponds to the color line peaks of the four selenatetreated samples. Linear combination fitting was used for the samples (Table 3).

the results of linear combination fitting for Se speciation in wheat tissues completed using Athena software.

There were substantial differences in Se speciation in plant tissues between selenite-treated plants and selenatetreated plants. In the selenite-treated plants cultured in normal nutrient solutions, most Se species in roots and 
Table 2. Results of linear combination fitting (LCF) of Se K-edge XANES data for tissues of wheat seedlings exposed to normal nutrient solution $(\mathrm{N})$ or nutrient solution without $\mathrm{S}(-\mathrm{S})$ with $10 \mu \mathrm{M}$ selenite for $3 \mathrm{~d}$.

\begin{tabular}{|c|c|c|c|c|c|c|c|}
\hline Sample type & $\begin{array}{l}\text { Se content } \\
{\left[\mathrm{mg} \cdot \mathrm{kg}^{-1}(\text { f.m. })\right]}\end{array}$ & R-factor & $\begin{array}{l}\text { Weight [\%] } \\
\text { selenate }\end{array}$ & $\mathrm{SeCys}_{2}$ & selenite & MeSeCys & SeOMet \\
\hline $\mathrm{N}+$ selenite - root & 9.17 & 0.000274 & 4.6 & 32.0 & 0.9 & 20.3 & 42.2 \\
\hline $\mathrm{N}+$ selenite - shoot & 0.75 & 0.016490 & - & 28.4 & 33.8 & 60.7 & - \\
\hline -S+selenite - root & 10.94 & 0.000396 & 6.2 & 29.8 & - & 19.5 & 44.5 \\
\hline
\end{tabular}

Table 3. Results of linear combination fitting (LCF) of Se K-edge XANES data for tissues of wheat seedlings exposed to normal nutrient solution $(\mathrm{N})$ or nutrient solution without $\mathrm{S}(-\mathrm{S})$ with $10 \mu \mathrm{M}$ selenate for $3 \mathrm{~d}$.

\begin{tabular}{llclrr}
\hline Sample type & $\begin{array}{l}\text { Se content } \\
{\left[\mathrm{mg} \mathrm{kg}^{-1} \text { (f.m.) }\right.}\end{array}$ & R-factor & $\begin{array}{l}\text { Weight [\%] } \\
\text { selenate }\end{array}$ & selenite & MeSeCys \\
\hline $\mathrm{N}+$ selenate - root & 1.43 & 0.014073 & 80.9 & 14.2 & 23.1 \\
$\mathrm{~N}+$ selenate - shoot & 2.25 & 0.007618 & 52.1 & 17.3 & 40.2 \\
-S + selenate - root & 6.33 & 0.016104 & 94.3 & 13.8 & 4.1 \\
-S + selenate - shoot & 17.03 & 0.016855 & 84.5 & 21.7 & 10.1 \\
\hline
\end{tabular}

shoots were present as species with spectra similar to organoselenium; and organoselenium in these plant tissues accounted for approximately $90 \%$ of the total Se. The organic forms identified in the selenite-supplied plants included $\mathrm{SeCys}_{2}, \mathrm{MeSeCys}$, and SeOMet (Fig. 2, Table 2). By contrast, in the selenate-treated plants cultured in normal nutrient solutions, the predominant $\mathrm{Se}$ species were present with spectra similar to selenate (Fig. 3), and the best fit of the XANES spectra indicated that the prevalent form was selenate $(80.9 \%$ of total Se), followed by MeSeCys (23.1\%) and selenite (14.2\%) in root tissues, and selenate (52.1\%), MeSeCys (40.2\%) and selenite $(17.3 \%)$ in shoot tissues (Table 3). Nevertheless, S starvation exhibited different effects on Se speciation between selenite-treated plants and selenate-treated plants. For plants exposed to selenate, $\mathrm{S}$ starvation increased the proportion of selenate and decreased the proportion of MeSeCys in both roots and shoots (Table 3). Whereas, for plants exposed to selenite, $\mathrm{S}$ starvation only slightly increased the proportion of selenate in the roots, but had no significant effect on proportion of organoselenium. Besides, results showed that various organic Se species differred in their mobility within plants (Tables 2 and 3). SeOMet were detected in higher proportion only in root tissues of selenite-treated plants, while MeSeCys was detected in higher proportions in shoots and roots of selenate-treated plants than in selenite-treated plants, indicating that MeSeCys was readily translocated from roots to shoots.

\section{Discussion}

The results of this study show that $\mathrm{S}$ starvation had a stronger stimulative effect on the uptake of selenate than selenite (Table 1), which is similar to the results of $\mathrm{Li}$ et al. (2008). Under S starvation, the differences of Se uptake by plants between selenite and selenate treatments may be attributed to the fact that plants take up selenate and selenite by dissimilar mechanisms. The researchers have demonstrated that sulphate transporters are involved in the uptake of selenate (Terry et al. 2000, Sors et al. 2005). The present study showed that $S$ starvation increased $\mathrm{S}$ uptake by plants, increased the content of $\mathrm{S}$ approximately by $40 \%$ in shoots and $10 \%$ in roots (Fig. 1). Under S starvation, plants might up-regulate the expression of sulphate transporter genes in roots (Buchner et al. 2004, White et al. 2004), leading to

greater uptake of selenate from external medium. However, other mechanisms are involved in the uptake of selenite. Li et al. (2008) showed that selenite uptake by wheat is inhibited by phosphate in the nutrient solution and enhanced by phosphorus starvation. Zhang et al. (2014) demonstrated that a phosphate transporter OsPT2 is involved in the active uptake of selenite, and also the overexpression of $O s P T 2$ can significantly increase selenite uptake and Se accumulation in plants. Thus, $\mathrm{S}$ starvation may have no significant effect on selenite uptake by wheat roots (Table 1).

Se speciation in plants varies with the form of Se fed to the plant. When plants were supplied with selenite, it was rapidly converted to organic forms and organic Se accounted for an average of $90 \%$ of the total Se in these 
plants (Fig. 1 and Table 3). By contrast, in the plants supplied with selenate, selenate remained by far the most dominant species in roots and shoots, with little amount converted to selenite and organoselenium species such as MeSeCys (Fig. 2 and Table 4). The results reported here agree with previous results involving HPLC-ICP-MS analysis (Kahakachchi et al. 2004, Li et al. 2008, Wang et al. 2015). The first step of selenate assimilation is its reduction to selenite via ATP sulphurylase, and then it is assimilated to SeCys (the precursor of organic Se compounds) via selenocysteine methytransferase. Once roots have taken up selenite, it is readily converted to other forms (Li et al. 2008). However, selenate absorbed by roots can be translocated without chemical modification to shoots via a sulphate transporter, and then metabolized in the chloroplasts via the sulphur assimilation pathway (Terry et al. 2000, Sors et al. 2005). Moreover, S starvation increased selenate uptake and consequently more selenate was detected in selenate treated plant. Over all, the present study demonstrated that selenite was assimilated rapidly in wheat roots, whereas selenate was hardly assimilated within $3 \mathrm{~d}$, indicating that the reduction of selenate to selenite is the rate-limiting step in selenate metabolism in plants (De Souza et al. 1998, Sors et al. 2005, Wang et al. 2015). Given that the reduction of selenate to selenite is the ratelimiting step in selenate metabolism, it is not surprising that organic Se forms were the dominant species in the selenite-treated plants, whereas selenate remained the dominant species in the selenate-treated plants (Tables 3 and 4$)$.

The most interesting finding of this study was that, in the selenite treatment, SeOMet was the dominant species and was detected only in root tissues (Table 3). Researchers have found that the addition of $\mathrm{Se}$ could result in decreased $\mathrm{H}_{2} \mathrm{O}_{2}$ content in rape seedlings (Filek et al. 2010) and marine red algae (Kumar et al. 2012), regardless of whether the plants were under abiotic stress. Moreover, researchers have found that Se may regulate the $\mathrm{O}_{2}{ }^{-}$and $\mathrm{H}_{2} \mathrm{O}_{2}$ production in stressed plants to protect plants against various stresses (Mittler 2002, Cartes et al. 2010, Chu et al. 2010, Yao et al. 2010). However, the associated mechanisms are still unclear; one hypothesis states that Se may regulate the ROS content through a direct reaction between Se-containing compounds and ROS (Feng et al. 2013). Here, we believe that one of the Se-containing compounds that react with ROS may be SeMet. In addition, SeOMet was detected in higher proportions only in the root tissues in the selenite treatments (Table 3), and this maybe the result of a reaction between SeMet and ROS. Moreover, the preparation of SeOMet in the laboratory may also demonstrate that the product of the reaction between SeMet and $\mathrm{H}_{2} \mathrm{O}_{2}$ is SeOMet (Larsen et al. 2004). Therefore, the results of this study indicated that selenite addition may be more effective than the addition of selenate in efforts to protect plants against abiotic stress.

In conclusion, the present study shows that the form of the Se that was supplied to plants greatly influenced Se accumulation and translocation in plants. Selenite taken up by roots was rapidly converted to organic forms and tended to accumulate in roots, whereas selenate was readily transported from roots to shoots, and remained as the most dominant species in both roots and shoots. Besides, $S$ starvation increased the proportion of inorganic Se species in the selenate-supplied plants, but had no significant effects on Se speciation in plants exposed to selenite. In addition, the present study indicated that selenite addition may be more effective than the addition of selenate in efforts to protect plants against abiotic stress.

\section{References}

Bañuelos, G.S., Walse, S.S., Yang, S.I., Pickering, I.J., Fakra, S.C., Marcus, M.A., Freeman, J.L.: Quantification, localization, and speciation of selenium in seeds of canola and two mustard species compared to seed-meals produced by hydraulic press. - Anal Chem. 84: 6024-6030, 2012.

Brown, K.M., Arthur, J.R.: Selenium, selenoproteins and human health: a review. - Public Health Nutr. 4: 593-599, 2001.

Buchner, P,. Stuiver, C.E.E., Westerman, S., Wirtz, M., Hell, R., Hawkesford, M.J., De Kok, L.J.: Regulation of sulfate uptake and expression of sulfate transporter genes in Brassica oleracea as affected by atmospheric $\mathrm{H}_{2} \mathrm{~S}$ and pedospheric sulfate nutrition. - Plant Physiol. 136: 33963408, 2004

Carey, A.M., Lombi, E., Donner, E., De Jonge, M.D., Punshon, T., Jackson, B.P., Guerinot, M.L., Price, A.H., Meharg, A.A.: A review of recent developments in the speciation and location of arsenic and selenium in rice grain. - Anal Bioanal. Chem. 402: 3275-3286, 2012.
Cartes, P., Jara, A.A., Pinilla, L., Rosas, A., Mora, M.L.: Selenium improves the antioxidant ability against aluminium-induced oxidative stress in ryegrass roots. - Ann. appl. Biol. 156: 297-307, 2010.

Chu, J., Yao, X., Zhang, Z.: Responses of wheat seedlings to exogenous selenium supply under cold stress. - Biol. Trace Element Res. 136: 355-363, 2010.

Combs, G.F.. Selenium in global food systems. - Brit. J. Nutr. 85: 517-547, 2001.

Cubadda, F., Aureli, F., Ciardullo, S., D’Amato, M., Raggi, A., Acharya, R., Reddy, R.A.V., Prakash, N.T.: Changes in selenium speciation associated with increasing tissue concentrations of selenium in wheat grain. - J. Agr. Food Chem. 58: 2295-2301, 2010.

De Souza, M.P., Pilon-Smits, E.A.H., Lytle, C.M., Hwang, S., Tai, J.C., Honma, T.S.U., Yeh, L., Terry, N.: Rate-limiting steps in selenium assimilation and volatilization by Indian mustard. - Plant Physiol. 117: 1487-1494, 1998. 
Feng, R.W., Wei, C.Y., Tu, S.X.: The roles of selenium in protecting plants against abiotic stresses.: Environ. exp. Bot. 87: 58-68, 2013.

Filek, M., Gzyl-Malcher. B., Zembala. M., Bednarska, E., Laggner, P., Kriechbaum, M.: Effect of selenium on characteristics of rape chloroplasts modified by cadmium. J. Plant Physiol. 167: 28-33, 2010.

Hawkesford, M.J., Zhao, F.J.: Strategies for increasing the selenium content of wheat. - J. Cereal Sci. 46: 282-292, 2007.

Hopper, J.L, Parker, D.R. Plant availability of selenite and selenate as influenced by the competing ions phosphate and sulfate. - Plant Soil 210: 199-207, 1999.

Kahakachchi, C., Boakye, H.T., Uden, P.C., Tyson, J.F.: Chromatographic speciation of anionic and neutral selenium compounds in Se-accumulating Brassica juncea (Indian mustard) and in selenized yeast. - J. Chromatogr. 1054: 303312, 2004.

Kápolna, E., Fodor, P.: Speciation analysis of selenium enriched green onions (Allium fistulosum) by HPLC-ICP-MS. Microchem. J. 84: 56-62, 2006.

Kumar, M., Bijo, A.J., Baghel, R.S., Reddy, C.R.K., Jha, B.: Selenium and spermine alleviate cadmium induced toxicity in the red seaweed Gracilaria dura by regulating antioxidants and DNA methylation. - Plant Physiol. Biochem. 51: 129-138, 2012.

Larsen, E.,H., Hansen, M., Paulin, H., Moesgaard, S., Reid, M., Rayman, M.: Speciation and bioavailability of selenium in yeast-based intervention agents used in cancer chemoprevention studies. - J. AOAC Int. 87: 225-232, 2004.

Li, H.F., Lombi, E, Stroud, J,L, McGrath, S,P, Zhao, F.J.: Selenium speciation in soil and rice: influence of water management and Se fertilization. - J. Agr. Food Chem. 58: 11837-11843, 2010.

Li, H.F., McGrath, S.P., Zhao, F.J.: Selenium uptake, translocation and speciation in wheat supplied with selenate or selenite. - New Phytol. 178: 92-102, 2008.

Mittler, R.: Oxidative stress, antioxidants and stress tolerance. Trends Plant Sci. 7: 405-410, 2002.

Ravel, B., Newville, M.: Athena, Artemis, Hephaestus: data analysis for X-ray absorption spectroscopy using IFEFFIT. J. - Synchrotron Radiat. 12: 537-541, 2005.

Rayman, M.P.: The importance of selenium to human health. -
Lancet 356: 233-241, 2000.

Rayman, M.P.: The argument for increasing selenium intake. Plant Nutr. Soc. 61: 203-215, 2002.

Rayman, M.P.: Selenium and human health. - Lancet 379: 1256-1268, 2012.

Rayman, M.P., Infante, H.G., Sargent, M.: Food-chain selenium and human health: spotlight on speciation. - Brit. J. Nutr. 100: 238-253, 2008.

Sors, T.G., Ellis, D.R., Salt, D.E.: Selenium uptake, translocation, assimilation and metabolic fate in plants. Photosynth. Res. 86: 373-389, 2005.

Terry, N., Zayed, A.M., De Souza, M.P., Tarun, A.S.: Selenium in higher plants. - Annu. Rev. Plant Biol. 51: 401-432, 2000.

Thomson, C.D.: Assessment of requirements for selenium and adequacy of selenium status: a review. - Eur. J. Clin. Nutr. 58: 391-402, 2004.

Wang, P., Menzies, N.W., Lombi, E., McKenna, B.A., James, S., Tang, C., Kopittke, P.M.: Synchrotron-based X-ray absorption near-edge spectroscopy imaging for laterally resolved speciation of selenium in fresh roots and leaves of wheat and rice. - J. exp. Bot. 66: 4795-4806, 2015.

White, P.J., Bowen, H.C., Parmaguru, P., Fritz, M., Spracklen, W.P., Spiby, R.E., Meacham, M.C., Mead, A., Harriman, M., Trueman, L.J., Smith, B.M., Thomas, B., Broadley, M.R.: Interactions between selenium and sulphur nutrition in Arabidopsis thaliana. - J. exp. Bot. 55: 1927-1937, 2004.

Williams, P.N., Lombi, E., Sun, G.X., Scheckel, K., Zhu, Y.G., Feng, X.B., Zhu, J.M., Carey, A.M., Adomako, E., Lawgali, Y., Deacon, C., Meharg, A.A.: Selenium characterization in the global rice supply chain. - Environ. Sci. Technol. 43: 6024-6030, 2009.

Yao, X., Chu, J., Ba, C.: Antioxidant responses of wheat seedlings to exogenous selenium supply under enhanced ultraviolet-B. - Biol. Trace Element Res. 13: 96-105, 2010.

Zhang, L.H., Hu, B., Li, W., Che, R.H., Deng, K., Li, H., Yu, F.Y., Li, H.Q., Li, Y.J., Chu, C.C.: OsPT2, a phosphate transporter, is involved in the active uptake of selenite in rice. - New Phytol. 201: 1183-1191, 2014.

Zhu, Y.G., Pilon-Smits, E.A.H., Zhao, F.J., Williams, P. N., Meharg, A.A.: Selenium in higher plants: understanding mechanisms for biofortification and phytoremediation. Trends Plant Sci. 14: 436-442, 2009. 